\title{
Erratum to: Is the SHRSP Strain a Suitable Model of Spontaneous CADASIL?
}

\author{
Silvana Penco • Paolo Gelosa • Silvana Pileggi • \\ Mauro Abbate • Alessandro Marocchi • \\ Uliano Guerrini • Alice Pignieri • Elena Tremoli • \\ Luigi Sironi
}

Published online: 7 June 2012

(C) Springer Science+Business Media, LLC 2012

\section{Erratum to: J Mol Neurosci}

\section{DOI 10.1007/s12031-011-9605-4}

The original version of this article unfortunately contained a mistake in the title and, specifically, in the acronym indicating the rat strain object of the study, the spontaneously hypertensive stroke prone rats, normally indicated as SHRSP and not SHRPS as erroneously reported in the title of the publication.

The correct title is then:

Is the SHRSP Strain a Suitable Model of Spontaneous CADASIL?

The online version of the original article can be found at http://dx.doi.org/ 10.1007/s12031-011-9605-4.

S. Penco $\cdot$ S. Pileggi $\cdot$ A. Marocchi

Department of Laboratory Medicine, Medical Genetics,

Niguarda Ca' Granda Hospital,

Piazza Ospedale Maggiore 3,

20162 Milan, Italy

P. Gelosa $\cdot$ U. Guerrini • A. Pignieri $\cdot$ E. Tremoli $\cdot$ L. Sironi $(\square)$ Department of Pharmacological Sciences, University of Milan, via Balzaretti 9,

20133 Milan, Italy

e-mail: luigi.sironi@unimi.it

\section{Abbate}

Department of Molecular Medicine, Mario Negri Institute for Pharmacological Research, Centro Anna Maria Astori,

Science and Technology Park Kilometro Rosso, via Stezzano 87,

24126 Bergamo, Italy

E. Tremoli $\cdot$ L. Sironi

Centro Cardiologico Monzino IRCCS,

via Parea 4,

20138 Milan, Italy 